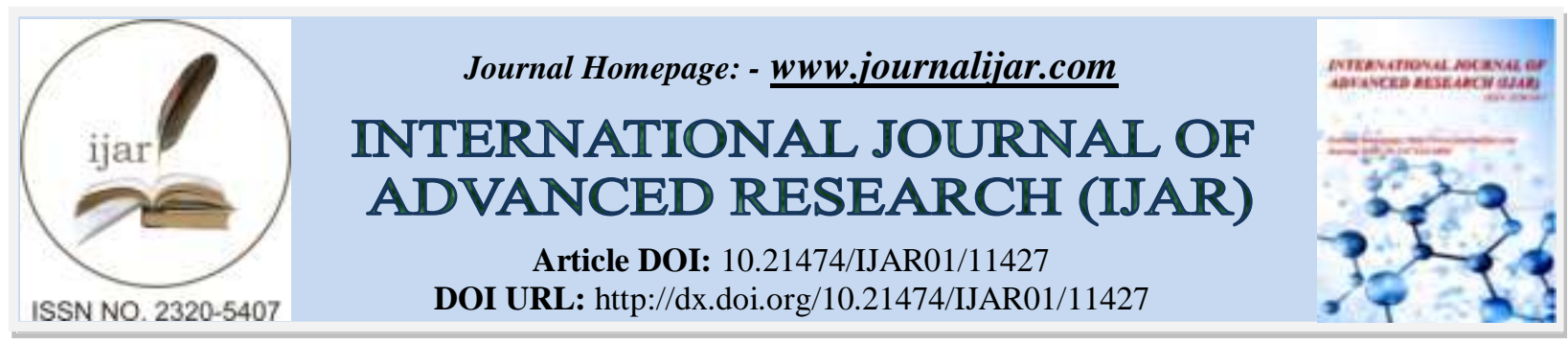

RESEARCH ARTICLE

\title{
APPROPRIATING ARCHITECTURAL DESIGN METHODOLOGY: BASED ON THE CONTEXT OF AN ABANDONED MINE
}

Suchi Priyadarshani, Dr. Mainak Ghosh and Soumyadeep Dutta

\section{Manuscript Info}

Manuscript History

Received: 28 May 2020

Final Accepted: 30 June 2020

Published: July 2020

Key words:-

Design Methodology, Architectural

Design, Architectural Anthropology,

People, Place, Time

\begin{abstract}
The challenges of design for an architect generally starts from the time he is approached by the client who might be the direct user to bring to the existence his requirements, which are filtered and expressed through analytical, creative, and technical skills of the architect and others involved in the process. However, the outcome of architecture is not only limited to the construction of a building but extends to the shaping of the entire community. Long term success of architecture is evaluated by evolving generations and is manifested through the measure of well-being of the society. In this context, the design program is one of the most vital elements that contribute to the success of architecture providing holistic solutions to all problems pertaining to the project. The question that comes with the understanding of this fact is whether the problem is correctly identified or not. It is the quintessential aspect before arriving at any desired proposition. This paper aims at demonstrating an all-inclusive comprehensive framework to assess the appropriateness of the architectural design program which is further substantiated with the able support of a case example in the context of an abandoned mine in global south.
\end{abstract}

Copy Right, IJAR, 2020, All rights reserved.

\section{Introduction:-}

The role of architects in the present world is not defined. Architects are creators, integrators, managers, advisors, and facilitators of the process of building space or a place. With the changing dynamics of work culture and increased scientific expertise in all technological domains, it is expected that the entire process starting from the conceptualisation to physical erection of the building is planned in a specific way in most cases where architects are given charge of it. As per the definition of an architect suggested by Merriam Webster Dictionary, an architect is a person who designs buildings and advises in their construction. If we look at the construction process itself, hundreds of people with different expertise are involved in the process and the collaborations between each of them become equally important (Herbert \& Donchin, 2016). An exhaustive list of people related to this industry like structural engineers, Plumbing and electrical experts, landscape designers, Masons, Carpenters, and so on put efforts and collaborate to bring into the environment a new entity (Burr \& Jones, 2010). The design process in architecture is unique to the kind of design itself. There has been a shift observed for the assessment of structures which has shifted from qualitative to empirical methods (Lloyd \& Scott, 1995). The assessments, however, are based on the basic principle proposed by Vitruvius, the father of architecture i.e. "Utilitas, Firmitas, and Venustas". This means that the building should be functional, structurally stable, and aesthetically pleasing (Robinson \& Of, 1955). The exhaustive process of architectural design generally starts from a design brief or a requirement given to the architect who then builds concepts to come up with a visualisation of the design. The design process adopted by an architect 
can be many (Demirbaş \& Demirkan, 2003). Buildings are man-made elements that connect the different layers of nature, society, culture, and integrates it to provide an appropriate environment to the occupant. However, the design methodology followed by the architect begins from a requirement, which nobody knows what effects it can lead to. The commencement of the design in the mind of the client who might or might not be the direct user of the buildings, however, is based on a set of perceptions. The technicalities of a holistic approach in this way are missing which might raise questions to the appropriateness of the functional use of the building itself. This leads to a huge loss of resources in the future. This happens especially in the case of public buildings. Imagining a shop in a forest and a residence in the middle of the road can be scary for many!

\section{Towards architectural design:}

As stated in the Bygghandbok fo"r hus-, va"g- och vattenbyggnad (1960), "The purpose of forecast and brief is to specify the general requirements a construction must reach to fulfil the intended purpose and to form a basis on which to compile the main data. Forecast and brief lead to a program on which to base the planning and design of the building and the technical work of construction and installation that follows'.

The best design makes the existence of the users easier without imposing it on them. Knowing the details of the context i.e. people, place, and time concerning that makes sure that one is not working on a wrong problem which in case of architecture happens to be guided by the brief or the program. Defining the problem is a crucial part of the process as it can lead to several implications of user satisfaction, strategic planning for completion of the building, political decisions, financial investments, procurement of people involved in the process, as well as on the people who get affected by the intervention indirectly. It is revealed in the literature that problem- solution in a design process co-evolve (Dorst \& Cross, 2001). However, these interactions lead to iterations sometimes at inappropriate moments when other things have to be compromised due to the already set boundary of limitations occurred due to progressed work at that moment. This leads to an emerging need to identify different ways which could facilitate the briefing process leading to an initiation more sensitive towards the social, physical, economical, and institutional function (Ryd, 2004).

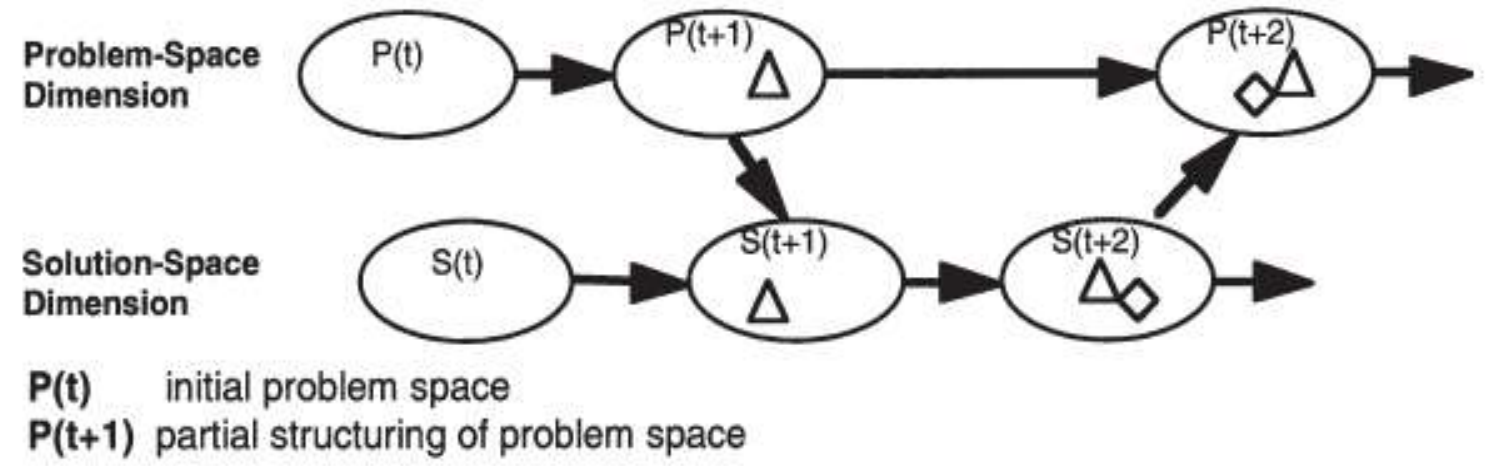

\section{$\mathbf{S}(t) \quad$ initial solution space $\mathbf{S}(\mathbf{t}+1)$ partial structuring of solution space}

\section{$\mathbf{S}(t+2)$ developed structuring of solution space $P(t+2)$ developed structuring of problem space}

Figure 1:- Adapted from (Dorst \& Cross, 2001)

The study ethnographic layers of the context can transform the notions of a particular perspective and broadens the designer's analytical and inventive abilities to look at divergent possibilities to the subject i.e. the architecture itself (Dank1, 2013). Also, the main idea remains to enhance the user satisfaction and tailoring of design intents to integrate the elements from the ethnographic understanding of the place and technical expertise of the architect (Sadowska \& Laffy, 2017). The crucial phase of decision making contributes a lot to reduce the environmental, economic, and social impact caused (Watson, W, \& R, 2000). 


\section{People:}

Users are active participants in making architecture work. The choices and preferences of individuals within the limits of the space of awareness reflects their aspirations based on the cultural influence they have (Urban, et al., 1978). The decision of the stakeholder who has the right to make decisions, in case of personal projects, the client itself affects the group of all other people who are the residents of the cultural, social, and environmental setting. The users get effected physiologically, psychologically, and behaviourally as well (Evans \& J.M, 1998).

Transition in space is important to make the space functionally viable and allow the users to adapt to it. An idea of creating an element of architecture which satisfies the users' requirements taking into consideration the satisfaction of the users around it to face minimal disturbance which they have already adapted to if not providing excellent opportunities to evolve (as per the perception of people considered as subjects) can be the least to be expected.

\section{Place:}

The role of "place", in architecture is not only limited to the design of a medium that amalgamates the ethnographic elements but also enhances the perspective of the identity of that place. Different architecture theories have evolved to bring this into the picture. The idea of critical regionalism discussed by Kenneth Frampton is the new approach for architecture for many contemporary architects (Frampton, 2002). Frampton in his essay argues that it is "critical to adopt" universal values of modernism, taking into account the geographical context of the building. Frampton does not want to refer directly to "folklore", but to the climate, light, topography, and "local tectonic form", which should be understood as historical and geographical conditions of the construction industry. This idea is advocated by many architects who have been considered stalwarts in the field across the world.

However, creating a building that respects the context and creating a building that is derived from the contextual requirements are two different things. The latter explains the evolution of the design and the requirements in terms of the brief guided by the contextual parameters itself, which proves to be of absolutely appropriate as its origin is backed by several facts from the context which guide the design process to make it a part of the contextual fabric in the most natural way, making it a way of guiding the design and construction process that is sustainable and acceptable.

\section{Time:}

$$
\text { "If I had asked people what they wanted, they would have said faster horses." -Henry Ford }
$$

The perception of people is based on the place they have lived in with different elements around them. This limit sets boundaries for the imagination of what can happen to deliver the requirement as to what should happen. By the virtue of educational expertise on the diverse field of architecture, the professionals develop an ability to understand things in a much diverse way. This knowledge is dynamic as it changes with the developing technology and trends around the world. To come up with a possible program for the design when done in this manner is much comprehensive, clear, and in line with current technologies to aid the process of creation.

\section{Context Case: Abandoned Opencast coal mine, Loyabad, Dhanbad (India)}

Dhanbad is generally referred to as the mineral capital of India city is situated in the state of Jharkhand is in the mineral belt of the country consisting of several open cast and underground coal mines. Apart from mineral resource reserve, this place is famous for dense forest and rich flora and fauna which houses several tribal communities in it. The onset of mining activities marked the deterioration of the various tribal communities as most of the mineral resources were under forest cover (Areeparampil). To extract resources forests were meeting the tribal groups vulnerable to many risks related to living conditions, loss of culture thereby affecting personal and community wellbeing (Lambin \& P, 2011) (Areeparampil). Many highlighted the issue of after mining effects which responsible for turning huge patches of land valueless.

The tourism policy 2016 released by the ministry of tourism, Government of Jharkhand outlined the types of tourism interventions that were focused by the authorities. Several interviews revealed that the abandoned mines were thought of being converted to tourist spots after the success of a few reclamation projects in Lodna area where abandoned mines were converted to parks (Hellotravel, 2018), (The Mining Information Clearinghouse of India (MICI), 2012). Abandonment of mines is a huge problem today as a potential land resource remains unutilized for years together and adds to the damage caused to the environment and society some of which are elaborated in (Singh, Ramanathan, \& Subramanian, 2018), (Giri, Singh, Jha, \& Tripathi, 2011), (Malaviya, Munsi, Oinam, \& 
Joshi), (Sinha, 1986). 297 abandoned mines in the country were identified before the up-gradation of regulations regarding the closure of mines (Indian Bureau of Mines, n.d.). Many countries have taken similar initiatives to convert abandoned mines into places of tourist attraction. In the context of Jharkhand, India, a focus of ecotourism led to proposals where the potential use for the mine was identified as ecotourism.

The paper aimed to assess the appropriateness of the identified design problem, i.e. the ecotourism site in a holistic way. The purpose of the study was to connect the theoretical knowledge, needs, and practical experience-based aspirations to re-arrive to a design problem that can be reasoned in a much comprehensive way.

\section{Framework:}

To conduct the study, a framework was designed (Figure 2) which is based on divergence-convergence principle. Using this process, a broader view of the possibilities can be obtained from an understanding of the different ethnographic layers of the context. These diverse possibilities can be converged slowly through several steps by can converge in further steps setting boundaries and elimination process which is based on expert opinion, aspirations of relevant stakeholders, the convenience of users and benefit, and satisfaction to the client if the same person is not the user. The set of data can be then in another step be filtered as per the priority as decided by the client. The entire process looks into the three aspects of viability (functionally and institutionally), feasibility (economically, environmentally, socially, and culturally) as well as acceptability (by client).

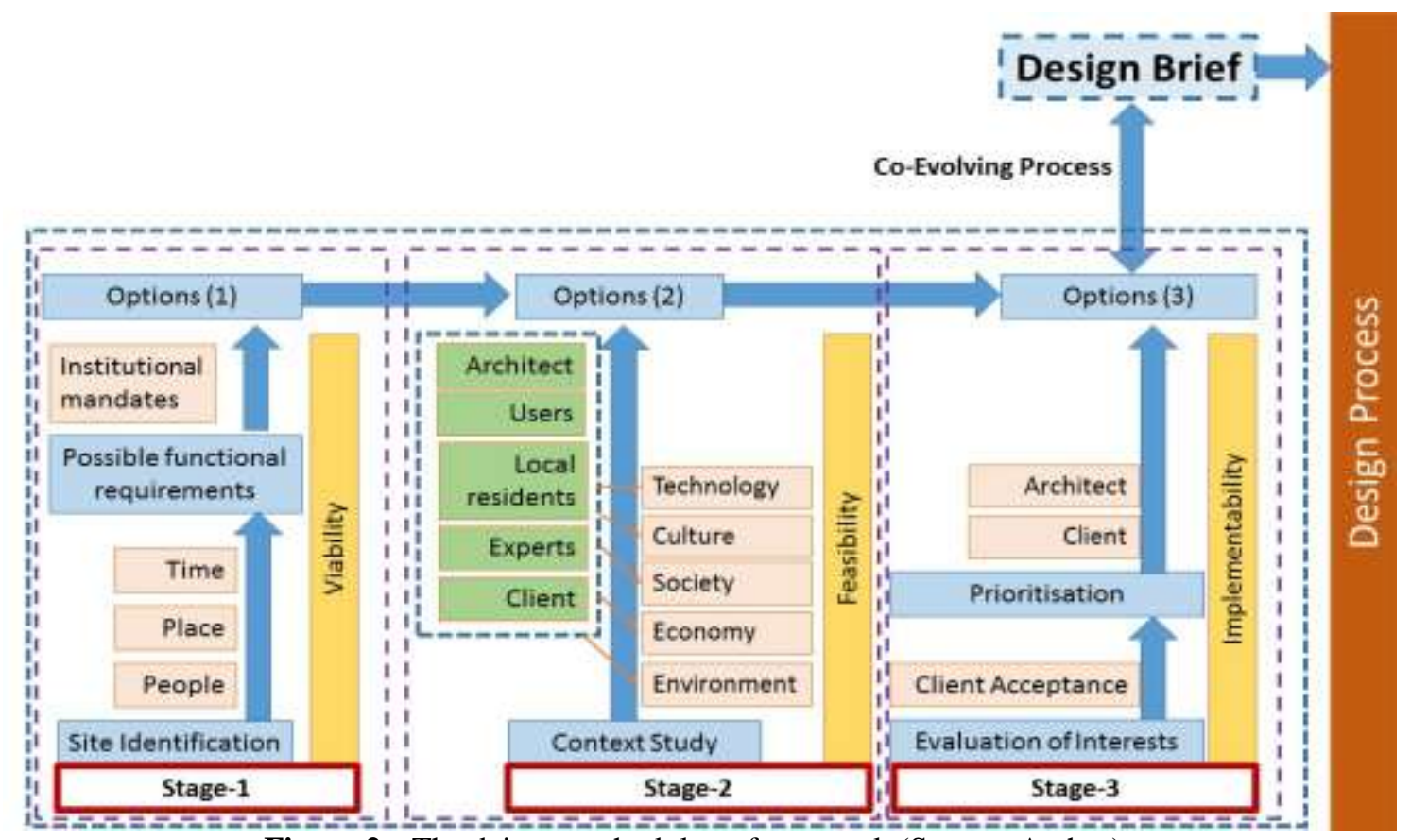

Figure 2:- The deisgn methodology framework (Source: Author).

\section{Results:-}

The understanding of the site demographics in terms of the environmental, socio-economic condition of residents, cultural relevance was studied. The data about demographics were obtained from the census database. A strong relevance with environment and culture was observed looking at the history of the place. The land had a huge forest cover before the commencement of mining activities. Also, a variety of tribal communities were residents of the forests who were displaced. The need for environmental restoration and preservation of the culture of the tribal groups was noted. Also, the location of the site happens to be in close vicinity to the National Highway which is part of the golden-quadrilateral transport network of the country making the adding value of great economic importance. The limitations were the topography that has changed due to mining and other environmental aspects like air pollution, land instability, and hardness of the water.

Understanding the feasibility of the creation of a tourist spot was studied by various surveys. These included an interview with the residents of the nearby areas about their aspirations and opinions, Interviews with officials of 
related administrative agencies, people with technical expertise in mining, Activists, Social workers, and Tourism facilitation agencies. The economic difficulties post-closure of mines was highlighted as one of the major problems of the people. Also, the quality of life led by the workers of the mines is bad. Unauthorized settlements with kachcha houses made of mud have been developed housing around 30 families. No infrastructural facilities like water supply, sewerage lines, transportation network, etc., is available. Women have to watch from $3 \mathrm{~km}$ to fetch drinking water.

The success of a tourist facility depends upon the interests of the tourists to a great extent. To understand this, another questionnaire survey was conducted. Responses from 219 subjects, 17-66 years of age were collected from across the country. $62.5 \%$ of the respondents had never visited a mine and expresses interest in it. $76.3 \%$ of the respondents mentioned that the first thing that comes in their mind when we talk about Jharkhand is mining. 49.8\% identified forests and $48.9 \%$ of respondents identified tribal are important in the identification of the heritage of the State. $1 \%$ of people mentioned about adventure sports, $0.5 \%$ talked about the industries, Hills, and, Religious places. 93.8\% of the respondents revealed that they were not aware of tribal culture and would like to experience it through workshops, training, and stays in relevant environments. The respondents also discussed cases where the abandoned mines have been used to create tourist spots in different ways. Some of the respondents negated the idea of utilising the abandoned mines due to the health hazards and at the same time, a few discussed the technological interventions that can be used to deal with it.

There is no "culture" without involving the people who are most affected by the plan and giving them agency--a voice--in it. The experience could be not so much about arts/crafts and museumifying / commodifying the site but about getting to know about the pros/cons of mining and how it impacts a region--its economy, ecology, and culture. - Anonymous Respondent

Subjective responses in the "other recommendations" clearly describe the diverse opinions of people based on their perceptions. The extraction of relevant results with the information obtained for assessment of the appropriateness of the purpose of a building ought to be subjective. It will be based on what parameters do the architect and the client prioritize with a mutual collaboration, however, this can lead to a far better understanding of the diverging scopes which can affect the user, society, and environment. The prioritization and convergence of all the results can thereby lead to reassurance and confidence towards the architecture.

\section{Discussions:-}

Several results highlight the fact that an overall rehabilitation of the place is necessary. This should accommodate the interests of not only the tourists and the stakeholders but also the people who have been suffering due to the mining activities. Interventions that can yield economic benefits and at the same time provide the opportunities for the revival of the lost culture, improvement in the well-being conditions of the people. Building an architecture should lead to the facilitation of basic amenities and essential services to facilitate lives rather than again displacing them in the name of creating a tourist spot. In this light, the possibility for rural tourism, and cultural tourism where the residents can actively participate and earn an opportunity to regain the essence of their rich culture and also help in the dissemination of the knowledge regarding the same which people have been unaware of through tourism can be reconsidered.

\section{Conclusion:-}

Hence extension of the process of architecture to the assessment of the appropriateness of purpose of architecture and thereby the derivation of an appropriate brief which suits the best to cater to the needs and requirements of all stakeholders and at the same time integrate the different layers of nature, society, culture technology and most importantly, occupants are very vital. This would not lead to the evolution of urbanscape to more functional, safe, and vibrant but also add values to make the architecture economically feasible, functionally viable, culturally relatable, and socially acceptable.

\section{Acknowledgements:-}

We are grateful to all the people who gave their valuable time for interviews and surveys for this study.

\section{References:-}

1. Areeparampil, M. (n.d.). Displacement due to mining in Jharkhand. Economic and Political Weekly, 31(24), pp. 1524-1528. Retrieved from http://www.jstor.org/stable/4404276 
2. Burr, K., \& Jones, C. (2010). The role of the architect: Changes of the past, practices of the present, and indications of the future. International Journal of Construction Education and Research, VI (2), 122-138. doi:https://doi.org/10.1080/15578771.2010.482878

3. Dankl, K. (2013). strategy and temporality: How to write an inclusive design brief? Design Journal, 16(2), 159174. doi:https://doi.org/10.2752/175630613X13584367984866

4. Demirbaş, O., \& Demirkan, H. (2003). Focus on architectural design process through learning styles. Design Studies, 24(5), 437-456. doi:https://doi.org/10.1016/S0142-694X(03)00013-9

5. Dorst, K., \& Cross, N. (2001). Creativity in the design process: Co-evolution of problem-solution. Design Studies, 22(5), 425-437. doi:https://doi.org/10.1016/S0142-694X(01)00009-6

6. Evans, G., \& J.M, M. (1998). When buildings don't work: The role of architecture in human health. Journal of Environmental Psychology, 18(1), 85-94. doi:https://doi.org/10.1006/jevp.1998.0089

7. Frampton, K. (2002). Towards a Critical Regionalism: Six Points for an Architecture of Resistance. Labour, Work and Architecture: Collected Essays on Architectural and Design, 76-89.

8. George, A. (2005). Laws related to mining in Jharkhand. Economic and Political Weekly, 1894(41), 44554458.

9. Giri, S., Singh, G., Jha, V. N., \& Tripathi, R. M. (2011). Risk assessment due to ingestion of natural radionuclides and heavy metals in the milk samples: A case study from a proposed uranium mining area, Jharkhand. Environmental Monitoring and Assessment, 175(1-4), 157-166. doi:https://doi.org/10.1007/s10661010-1502-8

10. Hellotravel. (2018). Jharkhand To Develop Abandoned Mines As New Tourist Spots. Retrieved November 16, 2019, from https://www.hellotravel.com/stories/jharkhand-to-develop-abandoned-mines-as-new-tourist-spots

11. Herbert, G., \& Donchin, M. (2016). The collaborators: Interactions in the architectural design process. In The Collaborators: Interactions in the Architectural Design Process. doi:https://doi.org/10.4324/9781315614816

12. Indian Bureau of Mines. (n.d.). Abandoned Mine Sites. Retrieved February 03, 2020, from http://ibm.nic.in/index.php?c=pages\&m=index\&id=90\&mid=21998

13. Karlen, D. (2008). Sustainability Indicators: A Scientific Assessment. In Journal of Environmental Quality, 37. doi:https://doi.org/10.2134/jeq2008.0005br

14. Lambin, E., \& P, M. (2011). Global land use change, economic globalization, and the looming land scarcity. Proceedings of the National Academy of Sciences of the United States of America, 108(9), 3465-3472. doi:https://doi.org/10.1073/pnas.1100480108

15. Lloyd, P., \& Scott, P. (1995). Difference in similarity: interpreting the architectural design process. Environment \& Planning B: Planning \& Design, 24(4), 383-406. doi:https://doi.org/10.1068/b220383

16. Malaviya, S., Munsi, M., Oinam, G., \& Joshi, P. K. (n.d.). Landscape approach for quantifying land use land cover change (1972-2006) and habitat diversity in a mining area in Central India (Bokaro, Jharkhand). Environmental Monitoring and Assessment, 1-4, 215-229. doi:https://doi.org/10.1007/s10661-009-1227-8

17. Ministry of Mines. (2019). NATIONAL MINERAL POLICY 2019. Government of India. Retrieved from https://mines.gov.in/writereaddata/Content/NMP12032019.pdf

18. Robinson, N., \& Of, J. (1955). Book III. Special Paper of the Geological Society of America (63), 36-60. doi:https://doi.org/10.1130/SPE63-p36

19. Ryd, N. (2004). The design brief as carrier of client information during the construction process. Design Studies, 25(3), 231-249. doi:https://doi.org/10.1016/j.destud.2003.10.003

20. Sadowska, N., \& Laffy, D. (2017). The design brief: inquiry into the starting point in a learning journey. The Design Journal, 20(Sup 1), S1380-S1389. doi:https://doi.org/10.1080/14606925.2017.1352664

21. Singh, U. K., Ramanathan, A. L., \& Subramanian, V. (2018, August). Groundwater chemistry and human health risk assessment in the mining region of East Singhbhum, Jharkhand, India. Chemosphere, 204, 501-513. doi:https://doi.org/10.1016/j.chemosphere.2018.04.060

22. Sinha, P. R. (1986). Mine fires in Indian coalfields. Energy, 11(11-12), 1147-1154. doi:https://doi.org/10.1016/0360-5442(86)90051-4

23. The Mining Information Clearinghouse of India (MICI). (2012, June 22). Abandoned Mines and FMCP in Jharkhand. Retrieved August 27, 2019, from http://samataindia.org.in/mici/2012-06-22-10-5353/minerals/states/54-jharkhand/136-abandoned-mines-andfmcp-in-jharkhand

24. Urban, P., G.F, C., P, C., C, P., D.R, D., A.K.F, F., \& D.P, O. (1978). Urban and Regional Planning Series. In Essays on Planning Theory and Education. doi:https://doi.org/10.1016/b978-0-08-021223-4.50020-7

25. Watson, S., W, C., \& R, H. (2000). Development of a Holistic Environmental Brief for use as a Design- phase Building Environmental Assessment Tool. Energy. 